\title{
Identification of reaction products between drug substances and excipients by HPLC- SPE-NMR: Ester and amide formation between citric acid and 5-aminosalicylic acid
}

Larsen, Jesper Tungelund; Stærk, Dan; Cornett, Claus; Hansen, Steen Honore'; Jaroszewski, Jerzy Witold

Published in:

Journal of Pharmaceutical and Biomedical Analysis

DOI:

10.1016/j.jpba.2008.12.028

Publication date:

2009

Document version

Publisher's PDF, also known as Version of record

Citation for published version (APA):

Larsen, J. T., Stærk, D., Cornett, C., Hansen, S. H., \& Jaroszewski, J. W. (2009). Identification of reaction products between drug substances and excipients by HPLC-SPE-NMR: Ester and amide formation between citric acid and 5-aminosalicylic acid. Journal of Pharmaceutical and Biomedical Analysis, 49, 839-842. https://doi.org/10.1016/j.jpba.2008.12.028 


\title{
Identification of reaction products between drug substances and excipients by HPLC-SPE-NMR: Ester and amide formation between citric acid and 5-aminosalicylic acid
}

\author{
Jesper Larsen $^{\mathrm{a}, *}$, Dan Staerk ${ }^{\mathrm{b}, \mathrm{c}}$, Claus Cornett ${ }^{\mathrm{a}}$, Steen H. Hansen ${ }^{\mathrm{a}}$, Jerzy W. Jaroszewski ${ }^{\mathrm{b}}$ \\ a Department of Pharmaceutics and Analytical Chemistry, Faculty of Pharmaceutical Sciences, University of Copenhagen, Copenhagen, Denmark \\ ${ }^{\mathrm{b}}$ Department of Medicinal Chemistry, Faculty of Pharmaceutical Sciences, University of Copenhagen, Copenhagen, Denmark \\ ${ }^{\mathrm{c}}$ Department of Basic Sciences and Environment, Faculty of Life Sciences, University of Copenhagen, Copenhagen, Denmark
}

\section{A R T I C L E I N F O}

\section{Article history:}

Received 30 September 2008

Received in revised form 17 December 2008

Accepted 17 December 2008

Available online 27 December 2008

\section{Keywords:}

HPLC-SPE-NMR

HPLC-MS

5-Aminosalicylic acid

Citric acid

Drug-excipient interactions

\begin{abstract}
A B S T R A C T
The reaction between the high-dose drug substance 5-aminosalicylic acid (5-ASA) and the excipient citric acid during storage of an experimental enema preparation has been studied and three isobaric reaction products, i.e., an ester and an amide with non-symmetrically substituted citric acid moieties and a symmetrical amide, were identified by combined use of HPLC-SPE-NMR and HPLC-MS. After storage for 1 week at $70^{\circ} \mathrm{C}$, approximately $5 \%$ of the 5 -ASA present in the formulation was transformed into these impurities. Storage of the enema for 32 months at room temperature led to loss of approximately $10 \%$ of the original amount of 5-ASA, with the ester as the main reaction product.
\end{abstract}

(c) 2008 Elsevier B.V. All rights reserved.

\section{Introduction}

The development of methods based on hyphenation of separation techniques and nuclear magnetic resonance (NMR) have greatly improved possibilities of identification of mixture components without the need of prior isolation and purification of individual compounds [1]. Thus, in contrast to well-established HPLC-MS methods, which are characterised by speed and high sensitivity but also by limited information content with respect to details of molecular structure, HPLC-NMR allows unambiguous on-line identification of even very complex structures. A recent extension of the original HPLC-NMR repertoire of experiments (comprising on-flow, stopped flow and loop-storage techniques $[1,2])$ is HPLC-SPE-NMR, where the analytes are separated from the HPLC mobile phase by means of post-column solid-phase extraction and then submitted, in an automated fashion, to NMR measurements in a deuterated solvent. Combined advantages of analyte focusing, accumulation by multiple SPE collections and the use of deuterated solvents makes HPLC-SPE-NMR capable of providing NMR data of higher quality than what is usually achievable by direct HPLC-NMR methods, i.e., methods where NMR

\footnotetext{
* Corresponding author. Tel.: +45 35336463

E-mail address: jl@farma.ku.dk (J. Larsen).
}

data are obtained with analytes dissolved in the HPLC mobile phase [2-4]. However, the HPLC-SPE-NMR technique is inherently dependent on the effectiveness of the post-column SPE process [5]. The HPLC-SPE-NMR technique is becoming increasingly popular, especially in natural products research [6-10], food and food supplement analysis [11,12], and pharmaceutical analysis [13], including analysis of drug degradation [14] and drug metabolism $[15,16]$. In this work, we describe the first example of application of HPLC-SPE-NMR to analysis of reaction products formed by interactions between a drug substance and an excipient upon storage of a pharmaceutical formulation.

For more than half a century, 5-aminosalicylic acid (5-ASA) has been used in the treatment of chronic inflammatory bowel diseases, originally in the form of the prodrug sulphasalazine [17] and subsequently as 5-ASA itself, and in the beginning of the 1980's the development of 5-ASA drugs accelerated [18-20]. Enemas are among the popular formulation forms for colonal delivery and are still very important in the treatment of distal colitis and proctitis $[21,22]$. The present text deals with the formation of impurities in an enema formulation of 5-ASA, that has been under development by a pharmaceutical company. It was important to elucidate the structures of the impurities in order to eliminate them from the final formulation. 5-ASA is used in relatively large doses and therefore has a potential of formation of relatively high amounts of potentially harmful impurities. 
Because 5-ASA is prone to oxidation, especially in alkaline solution, a number of excipients are usually added to 5-ASA solutions, including ethylenediaminetetraacetic acid, sulfite, and citric acid. The latter is widely used in pharmaceutical formulations as an acidifier, complexing agent or buffer substance. However, citric acid and other di- and polycarboxylic acids can form cyclic anhydrides, which can significantly increase their reactivity in the liquid as well as the solid state [23-25]. Recently, a reaction between 5-ASA and citric acid in a formulation produced by hot-melt technology has been reported, but no final conclusion about the structure of the reaction product was reached [26].

In high dose-drugs, an impurity present in an amount of $0.1 \%$ or more relative to the active substance has to be conclusively identified. This identification threshold often poses a considerable analytical challenge. Here, we describe identification of reaction products formed in liquid formulations from 5-ASA and citric acid using HPLC-SPE-NMR supported by HPLC-MS. The study thus addresses the problem of distinction between isomeric products formed with this widely used pharmaceutical excipient and is of potential interest for product control of liquid pharmaceutical formulations of drugs containing hydroxy and amino groups.

\section{Experimental}

\subsection{Materials}

Citric acid monohydrate and formic acid were purchased from Sigma-Aldrich Chemie (Steinhem, Germany). Methanol and phosphoric acid were purchased from VWR (Leicester, England). 5-Aminosalicylic acid (5-ASA) and $\mathrm{N}$-acetyl-5-aminosalicylic acid were obtained from Ferring Pharmaceuticals (Copenhagen, Denmark).

\subsection{High-performance liquid chromatography-mass spectrometry (HPLC-MS)}

HPLC-MS experiments were performed on an Agilent 1100 HPLC/MSD system (Agilent Technologies, Palo Alto, CA, USA). The chromatographic system consisted of a Phenomenex Luna $2 \times 100 \mathrm{~mm} 3 \mu \mathrm{m} \mathrm{C}_{18}$ column kept at $40^{\circ} \mathrm{C}$ and the mobile phases A $(10 \% \mathrm{MeOH}$ in water, added $0.1 \% \mathrm{HCOOH})$ and $\mathrm{B}(90 \% \mathrm{MeOH}$ in water, added $0.1 \% \mathrm{HCOOH}$ ). The gradient elution profile was $0 \% \mathrm{~B}$ at $0 \mathrm{~min}$, $20 \% \mathrm{~B}$ at $10 \mathrm{~min}, 50 \% \mathrm{~B}$ at 20 to $24 \mathrm{~min}, 0 \%$ B at $24.1 \mathrm{~min}$, with a flowrate of $0.3 \mathrm{~mL} / \mathrm{min}$ and a total runtime of $42 \mathrm{~min}$. UV traces were recorded at $240 \mathrm{~nm}$. The MSD was used in positive electrospray mode, drying gas flow $12 \mathrm{~L} / \mathrm{min}$, nebuliser pressure $40 \mathrm{psi}$, drying gas temperature $350^{\circ} \mathrm{C}$, capillary voltage $4 \mathrm{kV}$ and fragmentor $80 \mathrm{~V}$. The MSD was programmed to scan from 100-1200 a.m.u. with a cycle time of $1.08 \mathrm{~s}$. Samples were diluted appropriately with water; the total concentration was typically $0.5 \mathrm{mg} / \mathrm{mL}$ and the injection volume was $5 \mu \mathrm{L}$.

\subsection{High-performance liquid chromatography-solid-phase extraction-nuclear magnetic resonance (HPLC-SPE-NMR)}

The HPLC-SPE-NMR system consisted of an Agilent 1100 series chromatograph (quaternary pump, autosampler, column oven, photodiode array detector), a Knauer K100 Wellchrom post-column solvent delivery pump (Berlin, Germany), a Spark Prospekt 2 device (Emmen, Holland), and a Bruker Avance $600 \mathrm{MHz}$ NMR spectrom-<smiles>Nc1ccc(O)c(C(=O)O)c1</smiles>

5-ASA<smiles>O=C(O)CC(O)(CC(=O)O)C(=O)O</smiles>

citric acid<smiles>O=C(O)CC(O)(CC(=O)O)C(=O)Nc1ccc(O)c(C(=O)O)c1</smiles>

1<smiles>Nc1ccc(OC(=O)CC(O)(CC(=O)O)C(=O)O)c(C(=O)O)c1</smiles>

2<smiles>O=C(O)CC(O)(CC(=O)Nc1ccc(O)c(C(=O)O)c1)C(=O)O</smiles>

3<smiles>Nc1ccc(OC(=O)C(O)(CC(=O)O)CC(=O)O)c(C(=O)O)c1</smiles>

4<smiles>CC(=O)Nc1ccc(O)c(C(=O)O)c1</smiles>

N-Ac-5-ASA

Fig. 1. Structures of 5-ASA, citric acid, their esters and amides (1-4), and the model compound $N$-acetyl-5-ASA 


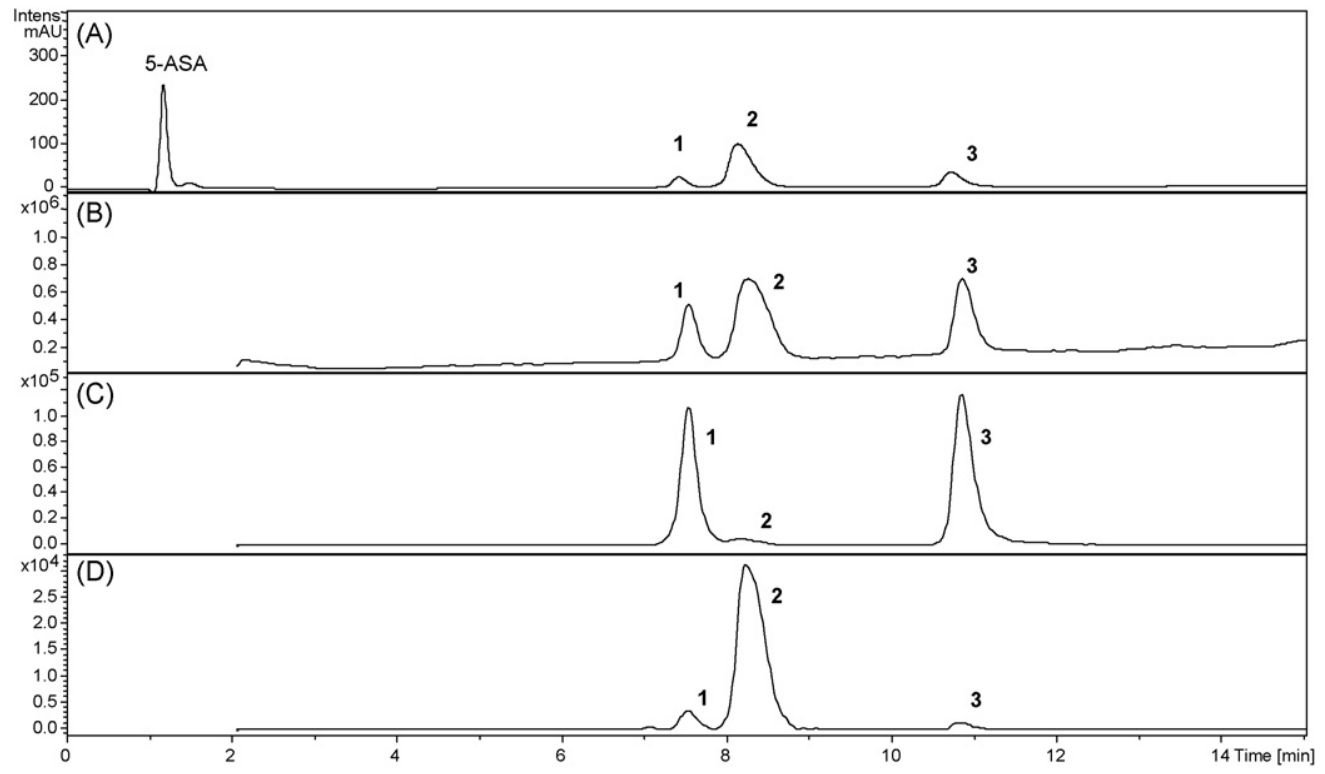

Fig. 2. HPLC-UV-MS chromatograms of enema formulation containing 5-ASA and citric acid after storage for 32 months at ambient temperature. (A) UV trace at $240 \mathrm{~nm}$. (B) Total ion chromatogram. (C) Extracted ion chromatogram $m / z$ 328. (D) Extracted ion chromatogram $m / z$ 310. Chromatographic conditions: Phenomenex Luna $C_{18}$ column eluted with a gradient of methanol in water (both containing $\mathrm{HCOOH}$ ) with UV and positive-ion electrospray MS detection (for details, see Section 2.2)

eter (Rheinstetten, Germany) equipped with a $3 \mathrm{~mm}(30 \mu \mathrm{L}$ active volume) ${ }^{1} \mathrm{H}\left\{{ }^{13} \mathrm{C}\right\}$ flow probe. The separations were performed at $40^{\circ} \mathrm{C}$ on a $10 \times 150 \mathrm{~mm}$ Phenomenex Luna $3 \mu \mathrm{m} \mathrm{C}_{18}$ column with a flow-rate of $0.8 \mathrm{~mL} / \mathrm{min}$. The mobile phase consisted of $35 \% \mathrm{MeOH}$ in water with $0.1 \% \mathrm{HCOOH}$ added. The post-column diluent was $0.1 \% \mathrm{HCOOH}$ in water, flow rate $2 \mathrm{~mL} / \mathrm{min}$. Injection volume was $100 \mu \mathrm{L}$. Threshold absorbance levels for analyte trapping were defined at $240 \mathrm{~nm}$ and six cumulative trappings on $2 \times 10 \mathrm{~mm}$ HySphere $\mathrm{C}_{18}$ HD cartridges were performed. Compounds were eluted from the SPE cartridges with methanol- $d_{4}$. The ${ }^{1} \mathrm{H}$ NMR spectra were calibrated to the residual solvent signal of methanol- $d_{4}$ at $\delta 3.31$.

\subsection{Stability of 5-ASA formulations}

An enema formulation containing $5.00 \mathrm{~g}$ 5-ASA, $0.10 \mathrm{~g}$ sodium edetate, $1.00 \mathrm{~g}$ sodium pyrosulfite, $5.00 \mathrm{~g}$ citric acid monohydrate, $1.75 \mathrm{~g}$ sodium hydroxide and $490 \mathrm{~g}$ purified water was investigated. The $\mathrm{pH}$ of the suspension was 4.8. The formulation was stored for 1 week at $70^{\circ} \mathrm{C}$. Another sample was stored at ambient temperature for 32 months. In both cases, the suspension was diluted ten-fold with water before being injected into the HPLC-MS system. To assess stability of the reaction products towards base, $500 \mu \mathrm{L}$ of the aged preparation was mixed with $500 \mu \mathrm{L}$ of $0.500 \mathrm{M} \mathrm{NaOH}$; after 5 min at ambient temperature an aliquot was mixed with equal amount of $0.500 \mathrm{M}$ phosphoric acid, diluted four-fold with water, and analysed immediately by HPLC-MS. A model mixture, containing $100 \mathrm{mg}$ 5-ASA and $100 \mathrm{mg}$ citric acid monohydrate in $1 \mathrm{~mL}$ water, was heated for $3 \mathrm{~h}$ at $70^{\circ} \mathrm{C}$ and the supernatant analysed by HPLC-SPE-NMR.

\section{Results and discussion}

In a pharmaceutical formulation containing both 5-ASA and citric acid, at least four primary reaction products 1-4, i.e., two amides ( 1 and $\mathbf{3}$ ), and two phenol esters ( 2 and $\mathbf{4}$ ), can be expected to be formed (Fig. 1). Formation of an ester of 5-ASA with the hydroxy group of citric acid is not expected, as tertiary alcohols do not form esters by direct esterification.

During a stability study of an enema formulation containing 5ASA as well as citric acid, formation of three new peaks (Fig. 2) was observed by HPLC-MS (retention times 7.6, 8.3 and $10.9 \mathrm{~min}$ ), and the same three products were formed upon treatment of the enema at $70^{\circ} \mathrm{C}$ for a week. All the peaks had $\mathrm{m} / \mathrm{z} 328$, corresponding to reaction products between 5-ASA and citric acid, although a water loss $(m / z 310)$ was so pronounced for the peak with retention time 8.3 min that intensity of the quasimolecular ion was low (Fig. 2).

In order to elucidate structures of the reaction products, a mixture of 5-ASA and citric acid was heated for $3 \mathrm{~h}$ at $70^{\circ} \mathrm{C}$ and the mixture was investigated by HPLC-SPE-NMR. An HPLC-MS investigation revealed reaction products with retention times and mass spectra identical to those formed in the real enema upon storage at room temperature or subjected to accelerated decomposition at $70{ }^{\circ} \mathrm{C} .{ }^{1} \mathrm{H}$ NMR data for all three products obtained from spectra recorded in the HPLC-SPE-NMR mode are collected in Table 1. The spectra are shown in Fig. 3.

Table 1

${ }^{1} \mathrm{H}$ NMR spectroscopic data ( $\delta$ values with intensities, multiplicities and coupling constants in $\mathrm{Hz}$ in parentheses) for main reaction products between 5 -ASA and citric acid, and for authentic $N$-acetyl-5-aminosalisylic acid (methanol- $d_{4}$ ).

\begin{tabular}{|c|c|c|c|c|c|c|}
\hline Compound & $\mathrm{H}-3$ & $\mathrm{H}-4$ & H-6 & Citric acid $\mathrm{CH}_{2}$ & & $\mathrm{~N}$-acetyl $\mathrm{CH}_{3}$ \\
\hline 1 & $6.90(1 \mathrm{H} ; \mathrm{d} ; 8.8)$ & $7.62(1 \mathrm{H} ; \mathrm{dd} ; 8.8,1.9)$ & $8.09(1 \mathrm{H} ; \mathrm{d} ; 1.9)$ & $\begin{array}{l}2.77(2 \mathrm{H} ; \mathrm{d} ; 15.6) \\
2.98(2 \mathrm{H} ; \mathrm{d} ; 15.6)\end{array}$ & & - \\
\hline 2 & 7.05 (1H; d; 8.8) & $7.40(1 \mathrm{H} ; \mathrm{dd} ; 8.8,2.4)$ & $7.80(1 \mathrm{H} ; \mathrm{d} ; 2.4)$ & $\begin{array}{l}2.98(1 \mathrm{H} ; \mathrm{d} ; 16.9) \\
3.13(1 \mathrm{H} ; \mathrm{d} ; 16.9)\end{array}$ & $\begin{array}{l}2.84(1 \mathrm{H} ; \mathrm{d} ; 18.4) \\
3.17(1 \mathrm{H} ; \mathrm{d} ; 18.4)\end{array}$ & - \\
\hline 3 & $6.88(1 \mathrm{H} ; \mathrm{d} ; 8.9)$ & $7.60(1 \mathrm{H} ; \mathrm{dd} ; 8.9,2.1)$ & $8.05(1 \mathrm{H} ; \mathrm{d} ; 2.1)$ & $\begin{array}{l}2.83(1 \mathrm{H} ; \mathrm{d} ; \text { overlap }) \\
2.97(1 \mathrm{H} ; \mathrm{d} ; 16.9)\end{array}$ & $\begin{array}{l}2.83(1 \mathrm{H} ; \mathrm{d} ; \text { overlap }) \\
2.90(1 \mathrm{H} ; \mathrm{d} ; 14.2)\end{array}$ & - \\
\hline$N$-Ac-5-ASA & $6.88(1 \mathrm{H} ; \mathrm{dd} ; 8.9,0.3)$ & 7.59 (1H; dd; 8.9, 2.7) & $8.06(1 \mathrm{H} ; \mathrm{dd} ; 2.7,0.3)$ & - & & $2.10(3 \mathrm{H} ; \mathrm{s})$ \\
\hline
\end{tabular}




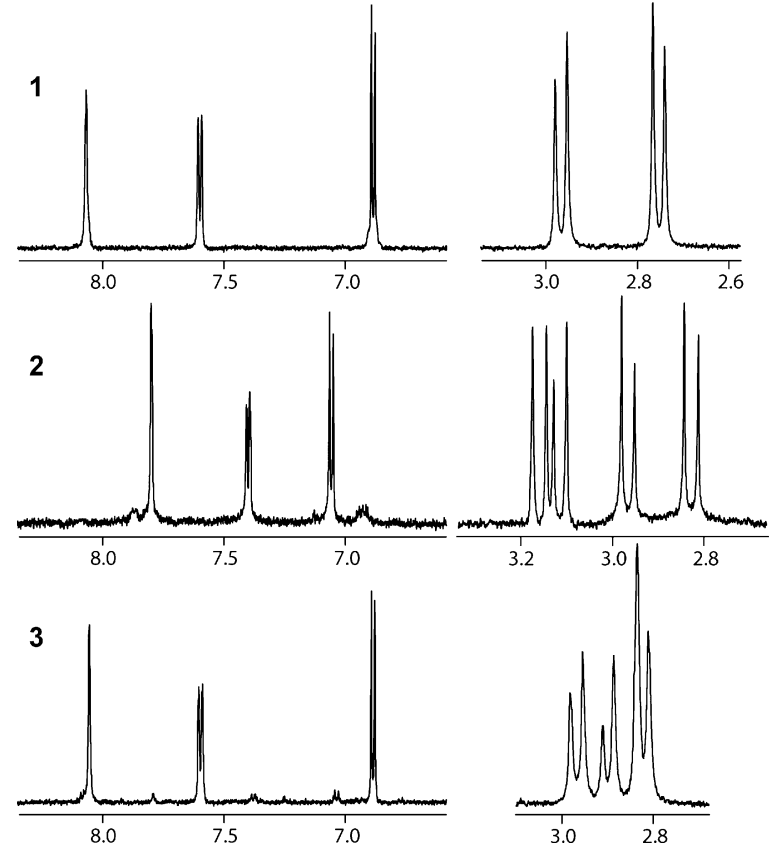

Fig. 3. ${ }^{1} \mathrm{H}$ NMR signals of reaction products between 5-ASA and citric acid obtained in HPLC-SPE-NMR mode $\left(600 \mathrm{MHz}\right.$, methanol- $d_{4}$, six trappings on $\mathrm{C}_{18}$ HD SPE cartridges).

It is apparent that the ${ }^{1} \mathrm{H}$ NMR spectrum recorded with the first of the three impurity peaks shows the presence of a symmetrically substituted citric acid moiety, as the spectrum contains one AB spin-spin coupling system with a geminal coupling constant between the diastereotopic methylene protons. By contrast, the spectra of the remaining compounds show the presence of two $A B$ systems each. The first impurity peak can therefore be either the amide $\mathbf{1}$ or the ester $\mathbf{4}$. The distinction between the ester and the amide can be made on the basis of chemical shifts within the benzene ring. Thus, comparison of the ${ }^{1} \mathrm{H}$ NMR spectrum with that of authentic $\mathrm{N}$-acetyl-5-aminosalicylic acid $(600 \mathrm{MHz}$ spectrum in methanol- $d_{4}$ recorded using a $5 \mathrm{~mm}$ tube) demonstrated, that the chemical shifts of the benzene ring protons of the two compounds are almost identical (Table 1). Therefore, the reaction product with the shortest retention time is the symmetric citric acid amide (1).

The remaining two impurity peaks must thus correspond to compounds 2 and $\mathbf{3}$ having non-symmetrically substituted citric acid moiety. Again, comparison of their ${ }^{1} \mathrm{H}$ NMR spectra with that of $\mathrm{N}$-acetyl-5-aminosalicylic acid (Table 1 ) demonstrated that the major impurity is the ester $\mathbf{2}$ and the impurity with the longest retention time is the amide $\mathbf{3}$ (cf. Fig. 2). Additional evidence was obtained by taking advantage of the fact, that phenol esters in contrast to amides are very labile towards alkaline hydrolysis. Thus, brief incubation of the aged enema formulation with alkali followed by acidification led to the disappearance of the major impurity peak corresponding to compound 2 , whereas the two minor peaks corresponding to compounds $\mathbf{1}$ and $\mathbf{3}$ were unchanged.

In the aged enema formulation (32 months), the amount of 5ASA converted to 1,2 and 3 was approximately $1.1 \%, 6.6 \%$ and $1.7 \%$, respectively (estimated by HPLC assuming the same absorptivity of the products at $240 \mathrm{~nm}$ ). Thus, almost $10 \%$ of the original amount of 5-ASA was lost via the reaction with citric acid. In the accelerated experiment ( 1 week at $70^{\circ} \mathrm{C}$ ), the approximate amount of impurities was $5 \%$, distributed as $0.5 \%, 4.0 \%$, and $0.5 \%$ of $\mathbf{1}, \mathbf{2}$ and $\mathbf{3}$, respectively.

\section{Conclusions}

The impurity profile for an enema formulation of 5-ASA with citric acid was investigated and the impurities formed upon storage were identified as compounds $\mathbf{1}, \mathbf{2}$ and $\mathbf{3}$. Formation of the symmetrical ester $\mathbf{4}$ was not observed, presumably because of steric hindrance around the central carboxy group of citric acid and thus negligible equilibrium concentration of this phenol ester. The identity of the products was established using the HPLC-SPE-NMR technique. Use of this hyphenated technique allowed acquisition of ${ }^{1} \mathrm{H}$ NMR data with a model formulation subjected to accelerated decomposition, leading to identification of the isobaric reaction products.

Because of a relatively rapid and extensive formation of reaction products between 5-ASA and citric acid, the use of citric acid in liquid 5-ASA formulations is not recommended. Thus, based on these findings, further development of a formulation of 5-ASA containing citric acid was abandoned and replaced with another formulation.

\section{Acknowledgement}

The authors would like to acknowledge the financial support from GEA Pharmaceutical A/S (Hvidovre, Denmark).

\section{References}

[1] K. Albert (Ed.), On-line NMR and Related Techniques, Wiley \& Sons, Chichester 2002.

[2] J.W. Jaroszewski, Planta Med. 71 (2005) 691-700.

[3] D. Stærk, M. Lambert, J.W. Jaroszewski, in: O. Kayser, W. Quax (Eds.), Medicinal Plant Biotechnology, 1, Wiley-VCH, Weinheim, 2006, pp 29-48.

[4] C. Seger, S. Sturm, LC-GC Europe 20 (2007) 587-597.

[5] C. Clarkson, M. Sibum, R. Mensen, J.W. Jaroszewski, J. Chromatogr. A 1165 (2007) $1-9$.

[6] V. Exarchou, M. Krucker, T.A. van Beek, J. Vervoort, I.P. Gerothanassis, K. Albert, Magn. Reson. Chem. 43 (2005) 681-687.

[7] J.W. Jaroszewski, Planta Med. 71 (2005) 795-802

[8] K. Sprogøe, D. Stærk, A.K. Jäger, A. Adsersen, S.H. Hansen, M. Witt, A.-K.R. Landbo, A.S. Meyer, J.W. Jaroszewski, J. Nat. Prod. 70 (2007) 1472-1477.

[9] S.S. Lee, Y.C. Lai, C.K. Chen, L.H. Tseng, C.Y. Wang, J. Nat. Prod. 70 (2007) 637642.

[10] E.C. Tatsis, S. Boeren, V. Exarchou, A.N. Troganis, J. Vervoort, I.P. Gerothanassis, Phytochemistry 68 (2007) 383-393.

[11] S. Christophoridou, P. Dais, L.H. Tseng, M. Spraul, J. Agric. Food Chem. 53 (2005) 4667-4679.

[12] C. Clarkson, D. Stærk, S.H. Hansen, P.J. Smith, J.W. Jaroszewski, J. Nat. Prod. 69 (2006) 1280-1288.

[13] M. Sandvoss, B. Bardsley, T.L. Beck, E. Lee-Smith, S.E. North, P.J. Moore, A.J. Edwards, R.J. Smith, Magn. Reson. Chem. 43 (2005) 762-770.

[14] C. Pan, F. Liu, Q. Ji, W. Wang, D. Drinkwater, R. Vivilecchia, J. Pharm. Biomed. Anal. 40 (2006) 581-590.

[15] M. Godejohann, L.H. Tseng, U. Braumann, J. Fuchser, M. Spraul, J. Chromatogr. A 1058 (2004) 191-196.

[16] S.M. Ceccarelli, G. Schlotterbeck, P. Boissin, M. Binder, B. Buettelmann, S. Hanlon, G. Jaeschke, S. Kolczewski, E. Kupfer, J.U. Peters, R.H. Porter, E.P. Prinssen, M. Rueher, I. Ruf, W. Spooren, A. Stämpfli, E. Vieira, ChemMedChem. 3 (2008) 136-144.

[17] M. Svartz, Acta. Med. Scand. 131 (1948) 465-472.

[18] S.N. Rasmussen, S. Bondesen, E.F. Hvidberg, S.H. Hansen, V. Binder, S. Halskov, Gastroenterology 83 (1982) 1062-1070.

[19] S. Bondesen, O.H. Nielsen, O.S. Jacobsen, N. Rasmussen, S.H. Hansen, S. Halskov, V. Binder, E.F. Hvidberg, Scand. J. Gastroenterol. 19 (1984) 677-682.

[20] M. Campieri, P. Gionchetti, A. Belluzzi, C. Brignola, M. Migaldi, G.M. Tabanelli, G. Bazzocchi, M. Miglioli, L. Barbara, Dig. Dis. Sci. 32 (1987) 67S-70S.

[21] J.K. Marshall, E.J. Irvine, Am. J. Gastroenterol. 95 (2000) 1628-1636.

[22] S.L. James, P.M. Irving, R.B. Gearry, P.R. Gibson, Int. Med. J. 38 (2008) 114119.

[23] T. Higuchi, T. Miki, A.C. Shah, A.K. Herd, J. Am. Chem. Soc. 85 (1963) 36553660.

[24] A.J. Repta, T. Higuchi, J. Pharm. Sci. 58 (1969) 1110-1114

[25] J. Larsen, C. Cornett, J.W. Jaroszewski, S.H. Hansen, J. Pharm. Biomed. Anal 49 (2009) 11-17.

[26] L.D. Bruce, N.H. Shah, A.W. Malick, M.H. Infeld, J.W. McGinity, Eur. J. Pharm. Biopharm. 59 (2005) 85-97. 